scien do Zagreb International Review of Economics \& Business, Vol. 24, Special Conference Issue, pp. 49-61, 2021 (C) 2020 Faculty of Economics and Business, University of Zagreb and De Gruyter Open

All rights reserved. Printed in Croatia

ISSN 1331-5609; UDC: $33+65$

DOI: $10.2478 /$ zireb-2021-0019

CONFERENCE PAPER

\title{
Critical Auditors' Expertise for Blockchain-Based Business Environment
}

\author{
Boris Tušek* \\ Ana Ježovita* \\ Petra Halar*
}

Abstract: The future of work of both external and internal auditors is exciting and promising, as well as, in the same time, threatening and extremely demanding. The exciting and promising part is connected with lots of possibilities for auditors' professional career developments and specialization, while the threatening and demanding part is directed towards the ongoing demand and need for continuous education and upgrading their knowledge base and skill sets in order to be able to stay up to date with all developments and changes in their and their clients' internal and external surroundings. Today these surroundings are characterized by big data and usage of information and communication technologies (ICTs), among which the blockchain technology (BCT) is described as the most pervasive and promising one. This paper is primarily driven by the scarcity of literature and conducted scientific researches regarding the specialized educations and expertise that auditors need to attend and possess in order to be able to exist in the blockchain-based business environment. Therefore, the main research objective of this paper was to determine critical external and internal auditors' expertise that they need to possess in order to be relevant and successful in the blockchain-based business environment. In order to achieve this main objective, desk research and survey research were conducted. Survey research was conducted on a sample of external and internal auditors in Croatia. In general, results of the empirical research showed that both external and internal auditors in Croatia think that they need to possess high level of expertise in advanced analytical procedures (APS) in order to be able to audit blockchain-based business operations. Consequently, this then instantaneously increases auditors' demand for specialized education in fields of BCT, APs, and data analytics (DAs) in general.

Keywords: external auditors; internal auditors; blockchain technology; analytical procedures; data analytics

\section{JEL Classification: $\mathrm{M} 42$}

* Boris Tušek, Ana Ježovita and Petra Halar are at Faculty of Economics and Business, University of Zagreb, Trg J. F. Kennedy 6, 10000 Zagreb, Croatia. 


\section{Introduction}

Contemporary external and internal auditing professions, as well as other similar economic professions, are faced with enormous amount of uncertainty, technological and non-technological disruptions, quest for survival, regulatory changes, and other various forms of insecurities. One important characteristic of modern economy is rapid development and pervasive influence of ICTs on all spheres of doing business and performing auditing activities, thus creating environment of big data. Among different types of existing ICTs, the BCT is quietly entering and profoundly changing traditional business and auditing operations. In other words, BCT can be seen as a key game changer ICT of the future that is constantly, day by day, gaining more and more prominence on the corporate governance agendas.

The effects of BCT on auditing can be seen via two parallel pillars. On the one hand, auditing is faced with constant improvements and digitalization of companies' business operations, and on the other, the audit firms and internal audit activities must be able to adapt to changes and innovations carried out by the BCT developments. Those challenges require from both external and internal auditors to upgrade their knowledge base and skill sets in order to be able to audit BCT as part of their audit objects and apply the appropriate audit techniques and procedures in all phases of audit engagements. Therefore, auditors will need to especially be prepared to cope with big data and risks generated by BCT and, as well, to apply appropriate APs and DAs in general to be able to provide adequate results that will improve companies' governance, risk management and internal controls.

Considering all that, the main research question of this paper can be stated as follows: what expertise auditors need to possess in order to be relevant and successful in the blockchain-based business environment? The subjects of this paper are external and internal auditors, their level of expertise in APs, as well as, other relevant types of expertise that auditors need to possess for dealing with BCT in contemporary era. Following the research question, the research objectives of this paper were derived, and they are as follows: to investigate and analyse the knowledge base and skills sets that auditors need to possess in order to be able to perform their work in blockchain-based business environment, and to determine whether there exist the need for more specialized education of auditors in the field of BCT, APs, and DAs in general. To investigate the main research question of the paper and to achieve defined research objectives, relevant literature was analysed and then empirical research was conducted on the sample of external and internal auditors in Croatia. 


\section{Literature review and research hypotheses}

$\mathrm{BCT}$ is one of the most disruptive and promising emerging technologies that has a great potential to significantly affect the auditing profession (Deloitte, 2017; Rooney, Aiken, \& Rooney, 2017; ICAEW, 2018; Wang \& Kogan, 2018; Cangemi \& Brennan, 2019; Kloch \& Little, 2019; Schmitz \& Leoni, 2019). BCT was first introduced as the core technology behind Bitcoin, Ether, and other cryptocurrencies, but in recent years, it has evolved far beyond these decentralized digital currencies, and is being applied in a broad range of business and financial operations (Deloitte, 2017; Rooney et al., 2017; Kloch \& Little, 2019). Blockchain, as a type of distributed ledger, can be best described as "a shared database that creates a permanent record of transactions. The database is shared across a network of multiple connected devices, which are known as "nodes." Whenever a new transaction is added to the ledger, the update is immediately viewable by all the other nodes on the network. In addition, the transactions - or blocks - are structured in a way that is designed to make it impossible to go back and change a previous entry" (Kloch \& Little, 2019, p. 4). The most important characteristics of BCT are transparency, immutability, interoperability, scalability, accuracy, performance, security, trustworthiness, disintermediation, traceability, persistency, distributed consensus approach, autonomous, decentralized, and secured capabilities (Rooney et al., 2017; Wang \& Kogan, 2018; Brender, Gauthier, Morin, \& Salihi, 2019; Cangemi \& Brennan, 2019). One way on which BCT can affect auditing is when it would be included in audit engagements, as audit object. This situation can appear when BCT is used within companies' business operations, when it represents part of its enterprise resource planning systems (ERPs) and accounting information systems (AISs) in order to provide realistic and objective financial reporting. BCT can be viewed as an essential accounting technology, because it has "the potential to increase the efficiency of the process of accounting for transactions and assets, operating as a system of universal entry bookkeeping" (ICAEW, 2018, p. 1). Because the $\mathrm{BCT}$ is a new and emerging technology, the rates of its implementation in companies may differ (Deloitte, 2019, p. 7). "Therefore, the preparedness level of each internal audit function to respond to the risks posed will also vary. But the overall challenge remains the same: Staying current on the risks and opportunities that come along with technological advancements such as BC" (Deloitte, 2019, p. 7).

In order for external and internal auditors to be able to audit blockchain-based business operations in the contemporary era of big data, the application of appropriate DAs techniques is indispensable. One of the most significant benefit of DAs' application is improvement in the effectiveness and efficiency of auditing activities (Lambrechts, Lourens, Millar, \& Sparks, 2011; KPMG, 2012; Cangemi, 2016; Chan \& Kogan, 2016; ICAEW, 2018; Ježovita, Tušek, \& Žager, 2018, p. 20), what is especially beneficial for auditing BCT and blockchain-based business operations. 
"Analytics is the science of analysis. Analysis is the process of disaggregating information into smaller parts to gain a better understanding of the data. Analytics should typically be a view from the top down to the detail. This allows for the analysis to be put in context" (Soileau, Soileau, \& Sumners, 2015, p. 11). DAs "is an analytical process by which insights are extracted from operational, financial, and other forms of electronic data internal or external to the organization. These insights can be historical, real-time, or predictive and can also be risk-focused (e.g., controls effectiveness, fraud, waste, abuse, policy/regulatory noncompliance) or performance-focused (e.g., increased sales, decreased costs, improved profitability, etc.) and frequently provide the 'how?' and 'why?' answers to the initial 'what?' questions frequently found in the information initially extracted from the data" (KPMG, 2012, p. 2). Understanding of DAs in contemporary big data environment implies "efficient tools, techniques and procedures used for comparing, forecasting, analysing and synthesizing available data in order to reach certain conclusions on patterns, anomalies, trends, expected values and to detect unexpected values and fluctuations that direct attention to problem areas and weaknesses of internal control system, business operations, management and other risks that organisations face" (Ježovita et al., 2018, p. 20). "Data analysis must be seen as another tool that can be used to achieve the objective of the specific audit" (Lambrechts et al., 2011, p. 3). ICTs' developments result in constructing new DAs techniques, or APs, which are getting more transparent, visually appealing, comprehensive, able to cover whole data sets and big data, and provide higher level of assurance for external and internal auditors.

As stated earlier, BCT, as an advanced ICT, represents significant challenge for auditors in the context of new auditing areas, as well as it demands for the application of new auditing methodologies and techniques, especially APs. According to author Halar (2020, p. 78), "most internal auditors still lack the appropriate competencies for assessing companies' digitally transformed business operations." More specifically, according to authors Kloch \& Little (2019, p. 11), the majority of the internal auditors have little or no familiarity with potential BCT applications in their organizations. In order for internal audit functions to be able to achieve its roles and responsibilities in the blockchain-based business environment, among all other possibilities, they need to invest in specialized educations of their human resources (Kloch \& Little, 2019, p. 13). The same situation in within the auditing firms. According to Deloitte (2017), external auditors will also need to broaden their skill sets and knowledge base in order to be able to audit in the blockchain-based business environment. In general, it is important to recognize that auditors will not need to be engineers who have detailed knowledge about how BCT functions, but they will have to know how to assure and advise on BCT usage and consider what impact will BCT have on business operations of their clients (ICAEW, 2018, p. 12). In specialized educations 
of both external and internal auditors, the emphasis should be placed especially on technological expertise that includes knowledge about specific BCT applications and functions in their clients' business operations, and about BCT in general, skills such as understanding technical programming language, coding and cybersecurity, as well as, knowledge and skills in advanced DAs and advanced APs (Deloitte, 2017; Kloch \& Little, 2019). Overall, it can be concluded, from conducted literature review that, on the global level, there is still lack of relevant literature and very little, if any, conducted scientific researches regarding the needed expertise and specialized educations of external and internal auditors in order to be able to exist and be ready for auditing blockchain-based business operations.

In the end, it can be stated that auditors need to possess high level of expertise and acquire appropriate knowledge about BCT, APs, and DAs in general to be ready to audit blockchain-based business operations for which they need specialized educations. Therefore, conducted literature review resulted in the statement of the following two research hypotheses that form the conceptual model of the research (Figure 1):

H1: Auditing blockchain-based business operations that require high level of expertise in advanced analytical procedures (APs) will increase auditors' demand for specialized educations.

$\mathrm{H} 2$ : The majority of auditors will need education in fields of blockchain technology $(B C T)$, analytical procedures (APs), and data analytics (DAs) in general to be ready to audit blockchain-based business operations.

Figure 1: Conceptual model of the research

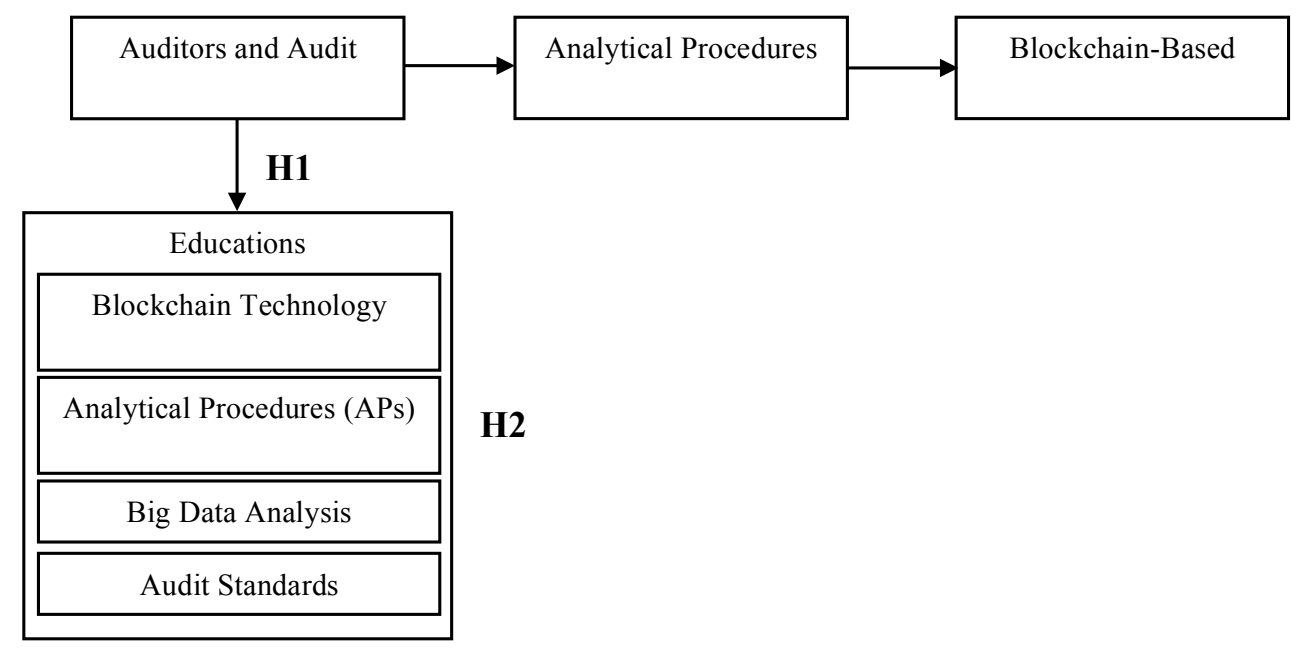

Source: Authors' creation. 


\section{Research methodology}

As we elaborated in the previous chapter, the research covers testing two research hypotheses regarding the demand for specialized educations which would improve auditors' skills to audit blockchain-based business operations that require a high level of expertise in advanced APs and which fields of education are the most important in that context. To test hypotheses, we surveyed Croatian external and internal auditors as individuals who perform audit engagements. The survey data were collected during April 2020 via LimeSurvey and processes with $R$ to obtain needed results.

The statutory auditing in Croatia is strictly regulated by European and Croatian legislative. As opposed to that, internal auditing is not regulated by a uniform legislative framework. Furthermore, only public sector entities and financial institutions in Croatia are obliged to establish an internal audit function, while for private sector entities it is not prescribed by law. The information is important in the context of determining the population of the research. Therefore, we are talking of two main aspects of the auditing profession - external audit and internal audit. Considering its legislation background, it was possible to determine that in April 2020 were 489 statutory (external) auditors in Croatia (Auditors Registry, Ministry of Finance, n.d.). On the other hand, in December 2019 there were 283 active certified internal auditors in the public sector (Ministry of Finance, 2020). However, there is no comprehensive publicly available database of internal auditors for the private sector in Croatia. Finally, the questionnaire was successfully sent to 498 external and internal auditors for which we managed to collect e-mail addresses. Over the two weeks, we received 172 responses suitable for this research what represents a response rate of $34.54 \%$.

To test research hypotheses, multiple regression analysis and binomial test were applied. The first research hypothesis that auditing blockchain-based business operations that require a high level of expertise in advanced APs will increase auditors' demand for specialized educations was tested by applying a multiple regression model. In general, multiple regression model of a dependent variable $Y$ on a set of $k$ independent variables $X_{1}, X_{2}, \ldots, X_{k}$ can be written as (1) (Aczel, 2008):

$$
Y=\beta_{0}+\beta_{1} X_{1}+\beta_{2} X_{2}+\ldots+\beta_{k} X_{k}+\varepsilon
$$

where $\beta_{0}$ is intercept, $\beta_{i}(i=1,2, \ldots, k)$ are regression coefficients, and $\varepsilon$ is an error term. The multiple regression analysis assumes that the expected autocorrelation between residuals, for any two observations, is 0 what can be written as $\operatorname{cov}(\varepsilon i$, $\varepsilon j)=0$. Mostly used approach for testing autocorrelation is the Durbin-Watson (DW) test. Perfect independence between residuals exists when DW is 2, i.e., in that case, there is no first-order linear autocorrelation. Furthermore, there should not be a multicollinearity problem (no linear relationship between independent variables) 
(Verma \& Abdel-Salam, 2019, p. 129). The most popular test of multicollinearity is the variance inflation factor (VIF). The value of 1 means that there is no multicollinearity problem.

The research premise is that regardless of existing expertise of auditors (ex_expertise), the implementation of new BCT (bct_imp) that requires the application of APs and DAs ( $b c t a p)$ would increase the demand for additional education of auditors to gain necessary skills for auditing that new business aspects (aud_edu). Therefore, the regression model, next to the dependent variable ( $a u d \_e d u$ ), has two independent variables (bct_imp and $b c t \_a p$ ) and one control variable (ex_expertise). The research model that will be tested can be written as (2):

$$
\text { aud_edu= } \beta_{0}+\beta_{1} b c t \_i m p_{1}+\beta_{2} b c t \_a p_{2}+\beta_{3} \text { ex_expertise }_{3}+\varepsilon
$$

The survey participants were asked if the education would be required, and if yes, in which field they would need the education to be trained and able to audit blockchain-based business operations. Responses are prepared as six binary variables and used to test the second research hypothesis. Variables are classified as binomial distribution $(B)$ with $k$ positive answers and $n$ examinees what can be written as (3) (Kobayashi, Mark, \& Turin, 2012):

$$
B(k ; n, p) \triangleq\left(\begin{array}{l}
n \\
k
\end{array}\right) p^{k} q^{n-k}, \quad k=0,1, \ldots, n
$$

where parameter $p \in[0,1], q \triangleq 1-p$ represents the probability of success on an individual trial, or in this research, represents the expected proportion of positive answers. From the statistical point of view, we will test if our empirical proportion is greater than the pre-specified theoretical proportion, or we will use a right-sided oneway binomial test with null hypothesis $H_{0}: \pi<p$ and alternative $H_{1}: \pi \geq p$ where $\pi$ is an empirical proportion of the sample.

\section{Empirical results and discussion}

As explained in the previous chapter, we managed to obtain responses from 172 external and internal auditors employed in Croatian entities. Information of years of auditing experience and the number of obtained certificates are used to assess the existing expertise of auditors covered by the research (Table 1). Most of the examinees (80.81\%) have more than 10 and only $4 \%$ of them have less than 5 years of experience in auditing (Table 1). In the context of certification, regulations in Croatia require at least 3-5 years of experience to be able to apply for the examination. 
Table 1: Year of experience of examinees

\begin{tabular}{|l|r|r|r|r|}
\hline & $<\mathbf{5}$ & $\mathbf{6 - 1 0}$ & $\mathbf{> 1 0}$ & $\mathbf{n}$ \\
\hline Years of experience & 7 & 26 & 139 & 172 \\
\hline$\%$ & 4.07 & 15.12 & 80.81 & 100.00 \\
\hline
\end{tabular}

Source: Authors' calculation.

At least one certificate has $97.67 \%$ of auditors included in the research, i.e., four examinees do not have any certificate relevant for the auditing profession (Table 2). Half of the examinees have a certificate for statutory auditor. Furthermore, of those examinees 23 or $27 \%$ of them additionally have a certificate for internal auditor and 9\% have some other certification (ACCA, CISA, CISM, AMBCI, FCCA, CPA, CTA). From the other angle, $37.21 \%$ of examinees have a certificate for internal auditor of which $36 \%$ additionally have a certificate for statutory auditor. Almost one-third (30.23\%) of examinees have a certificate for internal auditor in the public sector.

Table 2: Type of certificate obtained by examinees

\begin{tabular}{|l|c|c|c|c|c|}
\hline \multirow{2}{*}{ Type of Certificate } & \multicolumn{5}{|c|}{ Type of Certificate } \\
\cline { 2 - 6 } & stat_aud & int_aud & int_ps & other & \% in 172 \\
\hline sta_aud & $\mathbf{8 6}$ & 23 & 1 & 8 & 50.00 \\
\hline int_aud & 23 & $\mathbf{6 4}$ & 14 & 3 & 37.21 \\
\hline int_ps & 1 & 14 & $\mathbf{5 2}$ & 1 & 30.23 \\
\hline other & 8 & 3 & 1 & $\mathbf{1 2}$ & 6.98 \\
\hline $\begin{array}{l}\text { Legend: } \\
\text { sta_aud: statutory auditor } \\
\text { int_aud: certified internal auditor } \\
\text { int_ps: certified internal auditor in public sector } \\
\text { other (ACCA, CISA, CISM, AMBCI, FCCA,CPA,CTA and others) }\end{array}$ \\
\hline
\end{tabular}

Source: Authors' calculation.

Overall, 48 examinees, or $27.91 \%$ have at least two certificates, and only one examinee has three certificates. Therefore, 49 or $28.49 \%$ of examinees can be considered as multi-audit experts. Furthermore, 42 or $85.71 \%$ of multi-audit experts have more than 10 years of audit experience. On average, examinees have more than one certificate (1.24). Finally, it can be concluded that the survey covers $24.42 \%$ (42 of 172 ) of high expertise auditors. The newly formed binary variable (ex_expertise) is used as a control variable in a multiple regression model used for testing the first research hypothesis. 
Table 3: Descriptive statistics of chosen variables

\begin{tabular}{|c|c|c|c|c|c|c|c|}
\hline & mean & sd & median & trimmed & skew & kurtosis & se \\
\hline$b c t \_a p$ & 2.66 & 0.56 & 3.00 & 2.76 & -1.43 & 1.06 & 0.04 \\
\hline bct_imp & 3.68 & 0.73 & 4.00 & 3.67 & -0.32 & -0.08 & 0.06 \\
\hline aud_edu & 4.28 & 0.68 & 4.00 & 4.37 & -0.75 & 0.69 & 0.05 \\
\hline \multicolumn{8}{|c|}{$\begin{array}{l}\text { Legend: } \\
\text { bct_ap: BCT application (1-3) } \\
\text { ap_app: advanced APs application (1-5) } \\
\text { ap_inc: increase of APs application in case of BCT implementation (1-5) } \\
\text { aud_edu: need for education (1-5) }\end{array}$} \\
\hline
\end{tabular}

Source: Authors' calculation.

Descriptive statistics of the remaining variables included in the regression model are shown in the Table 3. With an average of 2.66 (out of 3) it can be concluded that most examinees consider that is crucial to have excellent knowledge and that application of APs in auditing blockchain-based business operations is inevitably (bct_ap). Therefore, results show (3.68 of 5) that the implementation of BCT would significantly influence the methodology and techniques used in audit engagements (bct_imp). In that context, the question is if the BCT implementation would create demand for additional educations. Results for the dependent variable show that out of 172 examinees, 68 of them strongly agree and 88 agree that education is necessary to obtain required cognitions, knowledge, and skills (aud_edu).

Results of the Durbin-Watson (DW) test with the value of 1.9936 and p-value .4859 show us that there is no autocorrelation problem between independent variables (Table 4). Furthermore, the variance inflation factor (VIF) is 1 based on which we concluded that there is no multicollinearity problem.

Table 4: Results of multiple regression analysis

\begin{tabular}{|c|c|c|c|c|c|c|}
\hline Coefficients & VIF & Estimate & Std. Error & $\mathrm{t}$ value & $\operatorname{Pr}(>|\mathrm{t}|)$ & \\
\hline (Intercept) & & 2.74225 & 0.31541 & 8.694 & 0.00000 & $* * *$ \\
\hline$b c t \_a p$ & 1.002654 & 0.21371 & 0.06838 & 3.125 & 0.00210 & $* *$ \\
\hline bct_imp & 1.000639 & 0.26429 & 0.06811 & 3.880 & 0.00015 & $* * *$ \\
\hline ex_expertise & 1.002159 & 0.02202 & 0.11430 & 0.193 & 0.84745 & \\
\hline $\begin{array}{l}\text { dependent va } \\
\text { Signif. codes: } \\
\text { Residual stan }\end{array}$ & $\begin{array}{l}-e d u \\
01 \text { '**'. } 01 \\
.6415 \text { on } 1\end{array}$ & $\begin{array}{l}.05: 1 \text { ، } \\
\text { legrees of } \mathrm{f}\end{array}$ & dom & & & \\
\hline \multicolumn{2}{|c|}{ Multiple R-squared: .1288, } & lue: 0.0000 & & & \multicolumn{2}{|c|}{ Adjusted R-squared: .1129} \\
\hline
\end{tabular}

Source: Authors' calculation. 
The independent variables in the model explain only $11.29 \%$ of the total variation in the dependent variable $(R 2=.1129)$. Although a low coefficient of determination suggests a poor fit of observations, the $\mathrm{F}(3,165)=8.129$ and p-value of .00004 confirms that the overall regression model is a good fit for the data. Results of the model show that two independent variable coefficients (bct_ap and bct_imp) are statistically significantly different from zero, i.e. they are statistically significant in the prediction of the dependent variable. By holding other independent variables constant, if the application of APs and DAs for auditing BCT (bct_ap) increases by one, the requirement for auditors' education to be able to audit new business aspects would increase by .2137 , and analogously, if the implementation of the BCT that will change techniques auditors apply in audit engagements (bct_imp) increases by one, the demand for education would increase by .2643. The third independent variable that represents existing auditors' expertise (ex_expertise) is not significant for the model what can lead us to the conclusion that the need for education related to the new DAs techniques and BCT is independent of the existing expertise of auditors. Consequently, we can confirm that the audit profession and contemporary business environment and digitalization processes assume lifelong learning. Therefore, it can be concluded that implementation of new BCT, as well as the application of advanced APs and DAs for auditing BCT, would increase demand for the educations of auditors. Taken all together, the results indicate that the first research hypothesis that auditing blockchain-based business operations that require a high level of expertise in advanced APs will increase auditors' demand for specialized educations (H1) can be accepted.

Following the result that education is required to obtain the necessary skills to use APs and DAs to audit BCT, the question is in which fields the education will be demanded. Our assumption stated in the second research hypothesis is that education will be needed in fields of BCT, APs, and DAs. Obtained results show that more than $88 \%$ of examinees consider they will need education in the field of BCT to be able to audit blockchain-based business operations. Additionally, more than $62 \%$ of examinees will need educations related to the application of advanced APs and DAs in general. It is interesting to notice that only $43 \%$ of examinees consider that they will need educations related to big data analysis and the application of auditing standards. For the research purposes, the majority from the second research hypothesis is defined as equal or more than half of the participants included in the research, i.e. parameter $p$ is .50 . The null hypothesis for most observed variables is $H_{0}: \pi<.50$ and an alternative $H_{1}: \pi \geq .50$ meaning that the true probability of success is greater than .50 . For every variable $n$ represents the number of examinees included in the research (172), and $k$ represents the number of positive answers. 
Table 5: Results of binomial test for chosen variables

\begin{tabular}{|l|c|c|c|c|}
\hline & $k$ of $n$ & $\begin{array}{c}\text { probability of } \\
\text { success }\end{array}$ & p-value & $p$ \\
\hline$e d u \_a l l$ & 170 & .988372 & .007486 & .95 \\
\hline$e d u \_b c t$ & 152 & .883721 & .000000 & .50 \\
\hline$e d u \_d a$ & 107 & .622093 & .000845 & .50 \\
\hline$e d u \_b d$ & 74 & .430233 & .971800 & .50 \\
\hline$e d u \_s t a$ & 74 & .430233 & .971800 & .50 \\
\hline
\end{tabular}

Source: Authors' calculation.

Almost all examinees (proportion of .9884) stated that they require education regardless of its field with significance at a level of $1 \%$ considering a p-value of .007486 (Table 5). More precise results show that more than $88 \%$ of examinees consider that they will need education related to BCT $\left(e d u_{-} b c t\right)$, and although at a lower level, still over half of the examinees, more precisely $62 \%$ of them, consider that they will need educations related to understanding and application of APs and DAs in general ( $e d u_{-}$ $d a)$ to audit blockchain-based business operations. Furthermore, $43 \%$ of examinees stated that they will need educations in the field of big data analysis $\left(e d u_{-} b d\right)$ or related to the recent changes of auditing standards related to the technology (edu_sta). Statements for $e d u \_b c t$ and $e d u \_d a$ that the probability of success is greater than .50 can be accepted at a significance level of $1 \%$ considering obtained p-values for both variables. Therefore, we can accept our second research hypothesis (H2) that most auditors will need education in fields of BCT, APs, and DAs to be ready to audit blockchain-based business operations.

\section{Conclusion}

Chaotic business environment and globalization processes followed with intensive digitization of business operations, which was especially emphasized during the last Covid-19 year, requires auditors to adjust their methodology, activities, and objectives. Nowadays lifetime learning is imperative. BCT, as a relatively new concept, represents great potential for a radical change of many business processes, from contracting, payments, bookkeeping, to compliance with tax regulations, digital IDs, monitoring supply chains, retail loyalty programs, and others. All those application opportunities challenge auditors to cope with new business aspects and force them to keep track of recent changes to be able to audit them. In that context, the application of advanced APs and DAs is crucial. Therefore, the most effective way to keep up with those challenges is to attend appropriate educations. Results of our research show that implementation of new BCT, as well as the application of advanced APs 
and DAs for auditing this new technology, would increase demand for the education of auditors regardless of their current expertise level. Furthermore, the most required educations would be related to BCT per se and gaining skills for the application of APs and DAs. Obtained results can be significant information for audit organizations and associations regarding the future development of external and internal auditing professions.

\section{REFERENCES}

Aczel, A. D. (2008). Complete business statistics. 7th Edition. USA: The McGraw-Hill/Irwin.

Auditors Registry, Ministry of Finance. Retrieved April 11, 2020, from http://rgfi.fina.hr/RegistarRevizora

Brender, N., Gauthier, M., Morin, J.-H., \& Salihi, A. (2019). The potential impact of blockchain technology on audit practice. Journal of Strategic Innovation and Sustainability, 14(2), 35-59. Retrieved from https://doi.org/10.33423/jsis.v14i2.1370

Cangemi, M. P. (2016). Views on internal audit, internal controls, and internal audit's use of technology. Journal EDPACS, 53(1), 1-9. Retrieved from https://doi.org/10.1080/07366981.2015.1128186

Cangemi, M. P., \& Brennan, G. R. (2019). Blockchain auditing - accelerating the need for automated audits! Journal EDPACS, 59(4), 1-11. Retrieved from https://doi.org/10.1080/07366981.2019 .1615176

Chan, D. Y., \& Kogan, A. (2016). Data analytics: Introduction to using analytics in auditing. Journal of Emerging Technologies in Accounting, 13(1), 121-140. DOI:10.2308/jeta-51463

Deloitte. (2017). Blockchain technology and its potential impact on the audit and assurance profession. Chartered Professional Accountants of Canada (CPA Canada) \& American Institute of CPAs (AICPA). Retrieved April, 11, 2020, from https://www.aicpa.org/content/dam/aicpa/ interestareas/frc/assuranceadvisoryservices/downloadabledocuments/blockchain-technology-and-its-potential-impact-onthe-audit-and-assurance-profession.pdf

Deloitte. (2019). An internal auditor's guide to blockchain: Blurring the line between physical and digital. Part one: Introduction to blockchain. Retrieved April 11, 2020, from https://www2. deloitte.com/content/dam/Deloitte/us/Documents/risk/us-risk-blockchain-for-internal-auditors.pdf

Halar, P. (2020). Postojeće stanje i perspektive profesionalnog razvoja internih revizora u dobu digitalne ekonomije. Zbornik Ekonomskog fakulteta u Zagrebu, 18(1), 77-94. Retrieved from https://doi.org/10.22598/zefzg.2020.1.77

ICAEW. (2018). Blockchain and the future of accountancy. The ICAEW IT Faculty. Retrieved April 11, 2020, from https://www.icaew.com/technical/technology/blockchain/blockchain-articles/ blockchain-and-the-accounting-perspective

Ježovita, A., Tušek, B., \& Žager, L. (2018). The state of analytical procedures in the internal auditing as a corporate governance mechanism. Journal of Contemporary Management Issues, 23(2), 15-46. Retrieved from https://doi.org/10.30924/mjcmi/2018.23.2.15

Kloch, R. C., \& Little, S. J. (2019). Blockchain and internal audit. The Internal Audit Foundation and Crowe. Retrieved April 11, 2020, from https://theiia.fi/wp-content/uploads/2019/08/ iaf-blockchain-internal-audit-july-2019-070119-2.pdf

Kobayashi, H., Mark, B. L., \& Turin, W. (2012). Probability, random processes, and statistical analysis. UK, Cambridge: Cambridge University Press. 
KPMG. (2012). Leveraging data analytics and continuous auditing processes for improved audit planning, effectiveness, and efficiency. Retrieved April, 11, 2020, from https://assets.kpmg/content/dam/kpmg/pdf/2016/05/Leveraging-Data-Analytics.pdf

Lambrechts, A. J., Lourens, J. E., Millar, P. B., \& Sparks, D. E. (2011). Data analysis technologies. IPPF: Recommended Guidance - Supplemental Guidance: Global Technology Audit Guide (GTAG) 16. Florida, Altamonte Springs: The Institute of Internal Auditors Global.

Ministry of Finance. (2020). Objedinjeno godišnje izvješće o sustavu unutarnjih kontrola u javnom sektoru Republike Hrvatske za 2019. Zagreb: Republic of Croatia, Ministry of Finance. Retrieved April, 11, 2020, from https://vlada.gov.hr/UserDocsImages//2016/Sjednice/2020/ Prosinac/32\%20sjednica\%20VRH//32\%20-\%2026\%20Objedinjeno\%20godi\%C5\%A1nje\%20izvje\%C5\%A1\%C4\%87e.pdf

Rooney, H., Aiken, B., \& Rooney, M. (2017). Q \& A. Is internal audit ready for blockchain? Technology Innovation Management Review, 7(10), 41-44. DOI: 10.22215/timreview/1113

Schmitz, J., \& Leoni, G. (2019). Accounting and auditing at the time of blockchain technology: A research agenda. Australian Accounting Review, 29(2), 331-342. Retrieved from https://doi. org/10.1111/auar.12286

Soileau, J., Soileau, L., \& Sumners, G. (2015). The evolution of analytics and internal audit. Journal EDPACS, 51(2), 10-17. Retrieved from https://doi.org/10.1080/07366981.2015.1012441

Verma, J. P., \& Abdel-Salam, A.-S. G. (2019). Testing statistical assumptions in research. USA, NJ, Hoboken: John Wiley \& Sons, Inc.

Wang, Y., \& Kogan, A. (2018). Designing confidentiality-preserving blockchain-based transaction processing systems. International Journal of Accounting Information Systems, 30, 1-18. Retrieved from https://doi.org/10.1016/j.accinf.2018.06.001 